\title{
The changing landscape of crack cocaine use and HIV infection
}

\section{David Celentano ScD MHS, Susan G. Sherman PhD MPH}

Previously published at www.cmaj.ca

$\infty \infty$

See related research article by DeBeck and colleagues, page 585

$\mathrm{U}$

se of crack cocaine was first recognized as a major public health problem in the United States two decades ago. It was quickly identified as a risk factor for HIV infection in association with high-risk sexual practices. ${ }^{1}$ Behaviours associated with injection drug use, including the sharing of contaminated needles, syringes and other drug paraphernalia, and unprotected sex are known risk factors for HIV transmission worldwide. However, with the increasing use of crack cocaine, little is known about its impact on the HIV epidemic.

In a linked research article, DeBeck and colleagues report that daily smoking of crack cocaine was an independent risk factor for HIV infection in a subset of people participating in the Vancouver Injection Drug Users Study $(n=1048) .{ }^{2}$ They divided the study into three distinct periods to reflect significant changes in patterns of crack cocaine use. The proportion of participants who reported daily smoking of crack cocaine rose from $11.6 \%$ in period 1 (May 1, 1996, to Nov. 30, 1999) to $39.7 \%$ in period 3 (Dec. 1, 2002, to Dec. 30, 2005). Among daily smokers of crack cocaine, the risk of HIV infection increased over time as well (hazard ratio [HR] 1.28, 95\% confidence interval [CI] 0.75-2.19 in period 1; HR 2.27, 95\% CI 1.44-3.61 in period 2; and HR 4.01, 95\% CI 1.79-8.96 in period 3).

The Vancouver Injection Drug Users Study, with its wellcharacterized study population, demonstrates the value of cohort studies in examining time-varying risk factors for disease outcomes. In the context of North America, a cohort study is the only design that permits a sufficient number of incident cases of HIV seroconversion and associated statistical power to reliably identify risk factors. Although many prospective cohort studies have examined risk factors for HIV seroconversion, none had examined the role smoking of crack cocaine has played.

The introduction of crack cocaine into an opiate-dependent population who injects drugs has changed the landscape of drug use and associated risks throughout North America. This in turn has had great consequences on the epidemiology of HIV infection among injection drug users, necessitating a broader focus on risk factors for HIV transmission, including work in the sex trade. This exemplifies the dynamic nature of drug use and the ability of cohort studies to capture these changes in real time.

Use of crack cocaine has been implicated in altering the immune system of HIV-positive women in one study, with effects including more rapid progression of HIV/AIDS,

\section{Key points}

- Daily smoking of crack cocaine is an independent risk factor for HIV infection among injection drug users.

- The mechanisms by which smoking of crack cocaine increases the vulnerability to HIV transmission are unknown.

- As a part of a comprehensive HIV prevention strategy, harm reduction programs should address the unique needs of people who smoke crack cocaine.

increased frequency of AIDS-defining illnesses and increased AIDS-related mortality. ${ }^{3}$ In addition, use of crack cocaine compromises the ability to make healthy decisions because of its short-term high, its highly addictive nature and its effects on neurocognitive functioning. ${ }^{4}$

The findings of DeBeck and colleagues should be viewed in light of several limitations. ${ }^{2}$ The authors were unable to sufficiently evaluate the mechanisms by which smoking of crack cocaine increases vulnerability to HIV transmission. They suggest that wounds in and around the mouth from using metal or glass pipes may make people who smoke crack cocaine more vulnerable to HIV transmission during activities such as oral sex or sharing of crack pipes. However, as noted by the authors, oral sex has not been shown to be significantly associated with HIV transmission. ${ }^{5}$ The authors' crude simplification of the intricacies of high-risk sexual behaviours into a dichotomy (ever v. never had unprotected sex) may have eliminated a possible significant association. For example, measures such as the number of sex partners, the proportion of sexual encounters that were unprotected and the frequency of unprotected oral sex might each have been implicated as a risk factor for HIV transmission. All of them are associated with smoking of crack cocaine.

The role of high-risk sexual behaviour among injection drug users, independent of injection behaviours, has been reported in two cohort studies over a 10 -year period. ${ }^{6,7}$ In a long-term cohort study of risk factors for HIV infection among injection drug users in the United States, high-risk sexual activity was found to be equally predictive of HIV incidence

David Celentano and Susan Sherman are with the Department of Epidemiology, Johns Hopkins Bloomberg School of Public Health, Baltimore, USA.

Cite as CMAJ 2009. DOI:10.1503/cmaj.091574

All editorial matter in CMAJ represents the opinions of the authors and not necessarily those of the Canadian Medical Association. 
as injection drug use. ${ }^{6}$ Among female participants, unprotected sex, as measured by self-reported sexually transmitted infections, was a significant predictor of HIV incidence. Among the male participants, significant risk factors were homosexual activity and cocaine injection. Much attention has been paid to the phenomenon of exchanging sex for crack cocaine as a primary risk factor for sexually transmitted infections among women who smoke crack cocaine. ${ }^{1,8}$ Although only a portion of people who smoke crack engage in the sex trade, data indicate this segment's increased risk of HIV infection and other sexually transmitted infections. ${ }^{9}$ Trading sex for crack cocaine is often viewed by people who use the drug as the most viable way to support their addiction. ${ }^{10}$

With the increasing proportion of injection drug users who are smoking crack cocaine, harm reduction programs need to address the unique needs of these people as part of a comprehensive HIV prevention strategy. Although controversial, the distribution of "crack kits" (glass stem with mouthpiece, metal screen, lip balm and hand wipes) to this population has the potential to reduce HIV transmission.

\section{Competing interests: None declared.}

Contributors: Both authors contributed equally to the conception and completion of the commentary, jointly drafted the article and gave approval of the final version submitted for publication.

\section{REFERENCES}

1. Edlin BR, Irwin KL, Faruque S, et al. Intersecting epidemics - crack cocaine use and HIV infection among inner-city young adults. N Engl J Med 1994;331:1422-7.

2. DeBeck K, Kerr T, Li K, et al. Smoking of crack cocaine as a risk factor for HIV infection among people who use injection drugs. CMAJ 2009. DOI:10.1503/cmaj.082054.

3. Cook JA, Burke-Miller JK, Cohen MH, et al. Crack cocaine, disease progression, and mortality in a multi-center cohort of HIV-1 positive women. AIDS 2008;22:1355-63.

4. Hoff AL, Riordan H, Morris L, et al. Effects of crack cocaine on neurocognitive function. Psychiatry Res 1996;60:167-76.

5. US Centers for Disease Control and Prevention (CDC). Can I get HIV from oral sex? Atlanta (GA): CDC; 2006. Available: www.cdc.gov/hiv/resources/qa /qa19.htm (accessed 2009 Aug. 31).

6. Strathdee SA, Galai N, Safaiean M, et al. Sex differences in risk factors for HIV seroconversion among injection drug users: a 10-year perspective. Arch Intern Med 2001;161:1281-8.

7. Kral AH, Lorvick J, Gee L, et al. Trends in human immunodeficiency virus seroincidence among street-recruited injection drug users in San Francisco, 19871998. Am J Epidemiol 2003;157:915-22.

8. Chiasson MA, Stoneburner RL, Hildebrandt DS, et al. Heterosexual transmission of HIV-1 associated with the use of smokable freebase cocaine (crack). AIDS 1991;5:1121-6.

9. Sterk C. Tricking and tripping: prostitution in the era of AIDS. Putnam Valley (NY): Social Change Press; 2000.

10. Logan TK, Cole J, Leukefeld C. Women, sex, and HIV: social and contextual factors, meta-analysis of published interventions, and implications for practice and research. Psychol Bull 2002;128:851-85.

Correspondence to: Dr. David Celentano, Department of Epidemiology, Johns Hopkins Bloomberg School of Public Health, Rm. E-6547, $615 \mathrm{~N}$ Wolfe St., Baltimore MD 21205, USA; fax410 955-1383; dcelenta@jhsph.edu

\section{SSIrone}

Sirona Biochem holds the key to enable exciting new drug candidates, aimed at better controlling Diabetes and Obesity.

Where others have tried and failed, Sirona has exclusive worldwide rights and rare expertise in the field of sugar molecule manipulation.

Combined with a lean business model and accelerated development cycle; recent positive test results serve to justify the company's pioneering

methods.

Learn more about Sirona at our web site or by calling our toll free number.

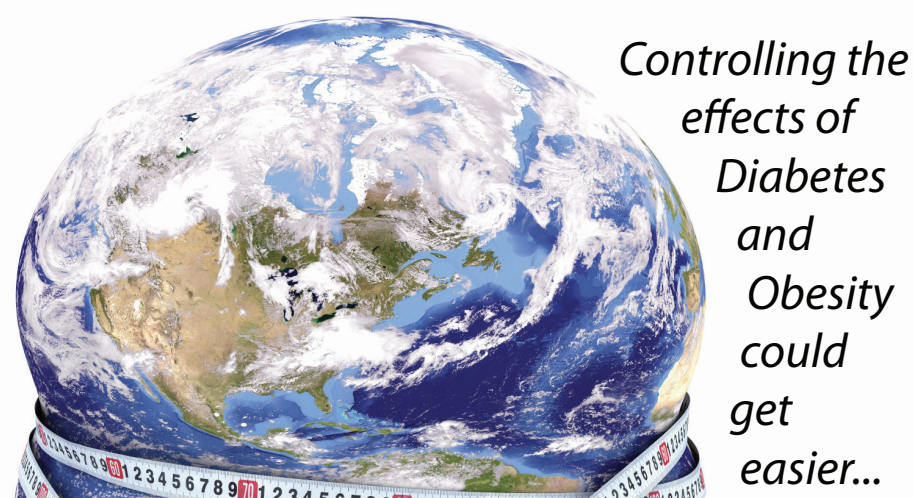

Controlling the Diabetes and Obesity could get easier..

\section{1-888-747-6621 wWW.sironabiochem.com Stock Symbol SBM:TSX.V}

